Research Paper

\title{
Comparison of the Analgesic Effect of Sufentanil versus Fentanyl in Intravenous Patient-Controlled Analgesia after Total Laparoscopic Hysterectomy: A Randomized, Double-blind, Prospective Study
}

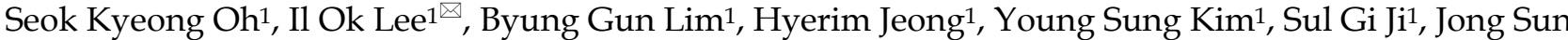 \\ Park $^{1}$
}

1. Department of Anesthesiology and Pain Medicine, Korea University Guro Hospital, Korea University College of Medicine, Seoul, Republic of Korea.

$\triangle$ Corresponding author: Il Ok Lee, Department of Anesthesiology and Pain Medicine, Korea University Guro Hospital, Gurodong-ro 148, Guro-gu, Seoul 08308, Republic of Korea; Tel.: 82-2-2626-1437; Fax: 82-2-2626-1438; E-mail address: iloklee@korea.ac.kr

(1) The author(s). This is an open access article distributed under the terms of the Creative Commons Attribution License (https://creativecommons.org/licenses/by/4.0/). See http://ivyspring.com/terms for full terms and conditions.

Received: 2019.03.05; Accepted: 2019.08.12; Published: 2019.09.20

\begin{abstract}
Background: Fentanyl is one of the most widely used opioids for intravenous patient-controlled analgesia (IV-PCA). Sufentanil, a fentanyl analog, is suitable for postoperative pain control because it has no active metabolites and shows a higher therapeutic index and lower frequency of respiratory suppression than fentanyl. This study aimed to compare the two opioids for postoperative pain relief on the basis of analgesic efficacy, adverse effects, and patient satisfaction.

Methods: Sixty-four patients undergoing total laparoscopic hysterectomy were randomly allocated into a fentanyl group $(n=31)$ or a sufentanil group $(n=33)$. The patients received $50-\mu g$ fentanyl or $10-\mu g$ sufentanil before induction of anesthesia and 5 minutes after uterine incision during surgery in the fentanyl and sufentanil group, respectively. After arriving at the post-anesthesia care unit (PACU), verbal pain score (VPS) and sedation score were assessed. IV-PCA (fentanyl $1250 \mu \mathrm{g}$ or sufentanil $250 \mu \mathrm{g}$ with ondansetron $8 \mathrm{mg}$; total volume, $60 \mathrm{ml}$ ) was connected and continued for $48 \mathrm{~h}$ postoperatively. Postoperative pain was evaluated by using the numeric rating scale (NRS; at rest/during cough) at $6,12,24,36$, and 48 hours after surgery. The cumulative PCA consumption, patient satisfaction scores, and adverse effects were measured.

Results: In the PACU, VPS was significantly higher and rescue fentanyl consumption was higher in the fentanyl group than in the sufentanil group, while the sedation score and adverse effects were comparable between the groups. No significant differences were observed in the NRS scores for pain (at rest/during cough) in the ward over 48 hours postoperatively, but the cumulative PCA consumption was significantly higher in the fentanyl group $(47.4 \pm 9.9 \mathrm{ml}$ vs. $36.2 \pm 14.6 \mathrm{ml}, P=0.01)$. There were no significant intergroup differences in patient satisfaction score and the incidence of adverse effects in the ward, except for a higher incidence of dry mouth in the fentanyl group.

Conclusions: In comparison with fentanyl, sufentanil showed comparable analgesic efficacy and safety with less analgesic consumption (under a potency ratio of 1:5) in IV-PCA after total laparoscopic hysterectomy. Therefore, we suggest that sufentanil can be a useful alternative to fentanyl for IV-PCA.
\end{abstract}

Key words: Patient-controlled analgesia, Fentanyl, Sufentanil, Postoperative pain, Hysterectomy.

\section{Introduction}

Intravenous patient-controlled analgesia (IVPCA) is frequently used to relieve postoperative pain in hospitalized patients by titrating analgesics on demand [1]. Opioids are typically used for IV-PCA, and fentanyl is one of the most frequently used opioids for this purpose [2] because of its enhanced analgesic efficacy and potency and fewer adverse effects than morphine or meperidine [3]. As a fentanyl analog, sufentanil is a highly lipophilic synthetic piperidine derivative opioid that has high affinity for 
$\mu$-opioid receptors and is suitable for postoperative pain control because it has no active metabolites and shows a higher therapeutic index and lower frequency of respiratory suppression than fentanyl [4]. Nevertheless, there have been few studies [5, 6] comparing fentanyl and sufentanil with respect to their analgesic efficacy for IV-PCA.

Total laparoscopic hysterectomy (TLH) is a commonly performed procedure in gynecological practice and offers advantages such as rapid recovery, less postoperative morbidity, reduced postoperative pain, and shorter hospital stay, in comparison with abdominal hysterectomy [7]. Despite these advantages, TLH is often followed by an unexpectedly high level of pain; because the pain after TLH is underestimated in comparison with that after abdominal hysterectomy, pain control is often inadequate, with comparably lower doses of opioid used [8]. Uncontrolled pain after surgery can reduce patient satisfaction, cause chronic postoperative pain development [9], and increase cardio-pulmonary complications and morbidity and mortality [10-12].

This study, therefore, was performed to compare the postoperative pain relief afforded by fentanyl and sufentanil in terms of their analgesic efficacies, including pain scores and opioid consumption, adverse effects, and overall satisfaction, in patients undergoing TLH. We hypothesized that sufentanil could provide comparable analgesic efficacy with lower postoperative respiratory depression than fentanyl in IV-PCA after TLH.

\section{Methods}

\section{Patients and study design}

This prospective double-blinded randomized study was approved by the Korea University Guro Hospital Institutional Review Board, Seoul, Republic of Korea (KUGH16346-001), and by the Ministry of Food and Drug Safety (MFDS, Korea), formerly known as the Korea Food and Drug Administration (KFDA), on December 23, 2016 (clinical trial approval number: 31136), and was conducted from April 2017 to January 2018 as a single-center trial. Written informed consent was obtained from every patient who was scheduled to undergo elective TLH under general anesthesia, was a female aged 19-75 years, and had an American Society of Anesthesiologists physical status I-II. Patients were excluded if they had body mass index $>30.0 \mathrm{~kg} / \mathrm{m}^{2}$, known hypersensitivity to the drugs used in this study, significant liver or renal dysfunction, or a history of drug abuse or dependence, recent major procedure or surgery, or preoperative analgesic use.

Participants were randomly assigned to either a fentanyl or a sufentanil group by a web-based computer-generated list and were unaware of their assignment. The randomized numbers were kept by the qualified clinical research pharmacist who managed the drugs; the drugs were delivered in a sealed opaque envelope before surgery; and the envelope was opened in the operating room only by a non-blinded anesthesiologist who was responsible for anesthesia management and setting the PCA pump as per the protocol in the operating room. Other investigators who assessed the study endpoints after the operation in the post-anesthesia care unit (PACU) and the ward were blinded to the group assignment. All the PCA devices were applied to patients with labels with only the patient's study number, so that neither the patients nor medical care providers and investigators could recognize the PCA regimen.

\section{Anesthesia and PCA regimen}

All patients were premedicated with intramuscular midazolam $2 \mathrm{mg}$ and glycopyrrolate $0.2 \mathrm{mg} 30$ minutes before anesthesia. In the operating room, all patients underwent routine physiological monitoring, which included pulse oximetry, electrocardiography, and noninvasive arterial blood pressure measurements. Bispectral index (BIS; BIS VISTA $^{\text {TM; }}$ Aspect Medical Systems Inc., Norwood, MA, USA) was determined to monitor the depth of hypnosis, and maintained from 40 to 60 during surgery.

For preemptive pain control and maintenance of hemodynamic stability during the initial phase of the operation, fentanyl $50 \mu \mathrm{g}$ in the fentanyl group and sufentanil $10 \mu \mathrm{g}$ in the sufentanil group were administered intravenously immediately before induction of anesthesia. Anesthesia was induced with intravenous administration of propofol $2 \mathrm{mg} / \mathrm{kg}$, followed by rocuronium $0.6 \mathrm{mg} / \mathrm{kg}$, which was administered after loss of consciousness (BIS < 60) to facilitate endotracheal intubation, and maintained with desflurane and $50 \%$ nitrous oxide in oxygen. The concentration (vol\%) of desflurane was guided by the BIS value. The core temperature was maintained at approximately $36^{\circ} \mathrm{C}$ using a warm air blower $\left(3 \mathrm{M}^{\mathrm{TM}}\right.$ Bair Hugger ${ }^{\mathrm{TM}}$ Intraoperative Blankets, $3 \mathrm{M}^{\mathrm{TM}}$, St. Paul, MN, USA). Five minutes after uterus incision, fentanyl $50 \mu \mathrm{g}$ in the fentanyl group and sufentanil 10 $\mu \mathrm{g}$ in the sufentanil group was administered to control the pain from surgical stimulus during surgery. At the end of the surgical procedure, neuromuscular blockade was reversed with glycopyrrolate $0.4 \mathrm{mg}$ and pyridostigmine $10 \mathrm{mg}$. Tracheal extubation was performed after confirming the response to verbal commands and spontaneous respiration. If mean arterial pressure decreased or 
increased by more than $30 \%$ from the baseline value, ephedrine $4 \mathrm{mg}$ or nicardipine $0.5 \mathrm{mg}$, respectively, was administered.

In the PCA protocol, the dose was based on a previous review article [13] and a recent study by Kim et al. [5] In the fentanyl group, IV-PCA was performed with fentanyl $1250 \mu \mathrm{g}$ and ondansetron 8 mg mixed with $0.9 \%$ isotonic saline to a total volume of $60 \mathrm{ml}$, whereas the patients in the sufentanil group received IV-PCA with sufentanil $250 \mu \mathrm{g}$ and ondansetron $8 \mathrm{mg}$ mixed with $0.9 \%$ isotonic saline to a total volume of $60 \mathrm{ml}$. The PCA device used in the study was Anaplus ${ }^{\circledR}$ AP0605 (E-WHA biomedics, Seoul, Republic of Korea) as an elastomeric pump, with a basal rate of $0.5 \mathrm{ml} / \mathrm{h}$, and a lockout period of 15 minutes, and a single bolus injection volume of 0.5 $\mathrm{ml}$ and maximal volume of $60 \mathrm{ml}$; thus, the maximal limit per hour was $2.5 \mathrm{ml}$. Through this PCA device, the fentanyl group received a basal infusion of 10.4 $\mu \mathrm{g} / \mathrm{h}$ with a bolus dose of $10.4 \mu \mathrm{g}$ over 15 minutes and the sufentanil group received a $2.08-\mu \mathrm{g} / \mathrm{h}$ basal infusion with a bolus dose of $2.08 \mu \mathrm{g}$ over 15 minutes.

\section{Postoperative recovery and pain management}

After arrival at the PACU, the patient's pain level was evaluated according to a verbal pain score (VPS; $0-3 ; 0=$ no pain, $1=$ mild pain, $2=$ moderate pain, $3=$ intense pain) [14] at 10-minute intervals, and the sedation score $(0-3 ; 0=$ clearly conscious; $1=$ temporarily drowsy; $2=$ drowsy but responsive to verbal communication; and $3=$ drowsy without response to verbal communication) [14] was also assessed at 10 -minute intervals. Fentanyl $20 \mu \mathrm{g}$ was administered if the patient showed VPS $\geq 2$, respiratory rate $\geq 10$ per minutes, $\mathrm{SpO}_{2} \geq 95 \%$, and sedation score $\leq 1$. When the VPS and the sedation score were $\leq 1$, the PCA device was connected and PCA was commenced. If the VPS was not $\leq 1$ despite repetitive rescue injections of fentanyl $20 \mu \mathrm{g}$ at 10 -minute intervals over 2 hours, the case was considered to represent failure in pain control and excluded from the analysis group.

After the patients were transferred to the ward, and the pain level was evaluated according to a numeric rating scale (NRS; 0-100; no pain [0] to worst pain imaginable [100]) at 6, 12, 24, 36, 48 hours after surgery. The cumulative consumption of PCA over 48 hours and the occurrence of adverse effects (e.g., nausea and vomiting, dry mouth, dizziness, urinary retention, headache, sedation, itchiness, shivering, respiratory depression, confusion, hypotension, and bradycardia) were assessed. Respiratory depression was defined by respiratory rate $<10$ per min or oxygen saturation $<90 \%$ for $>1 \mathrm{~min}$ [15]. The patient's overall satisfaction score $(0-3 ; 0=$ un-satisfied, $1=$ partial-satisfied, 2 = satisfied, 3 = full-satisfied) was also evaluated. If the postoperative pain control in the ward was insufficient (NRS score for pain > 30), $50 \mu \mathrm{g}$ of fentanyl as a rescue analgesic was planned to be administered. The duration of action of intravenous fentanyl is known to be 30 to 60 minutes; therefore, the rescue dose was not administered at least $1 \mathrm{~h}$ before the evaluation time points; but if it was inevitable, the evaluation time point was delayed by 1 $\mathrm{h}$ after the administration.

\section{Evaluation of outcomes}

The outcomes measured included (1) VPS (0-3) measured every 10 minutes at the PACU; (2) the sedation score (0-3) measured every 10 minutes at the PACU; (3) rescue fentanyl administration in the PACU; (4) PCA connection time at the PACU (min); (5) NRS score (0-100) at rest and during cough in the ward (primary endpoint); (6) patient's overall satisfaction score (0-3); (7) cumulative PCA consumption (ml); (8) occurrence of side effects in the PACU and in the ward for 48 hours after PCA connection.

\section{Statistical analysis}

A pilot study prior to the study was impossible because the use of sufentanil for PCA in Korea was not approved by the MFDS, Korea, formerly known as the KFDA. However, based on a previous similar study [5] that examined 42 patients per group, we calculated the sample size expecting to obtain similar results in our study. If the lower boundary for the difference in the pain score at 24 hours after surgery was not less than $-10 \%$, sufentanil treatment would be considered non-inferior to fentanyl treatment. On the basis of the assumption that the allocation ratio of the two groups was 1, a sample size of 29 patients was selected for each group, calculated by a non-inferiority test with a significance level of 0.05 , power of 0.9 , and non-inferiority margin of $10 \%$. We aimed to assign 35 patients to each group after accounting for $15 \%$ drop-outs.

Statistical analyses were performed using the SPSS software (version 20.0; IBM, USA). The normal distribution of continuous data was first evaluated using the Shapiro-Wilk test $(P>0.05)$. The normally distributed data were analyzed using Student's t-test, and the abnormally distributed data were analyzed using Mann-Whitney U test. Student's t-test was used to compare the age, height, weight, anesthesia time, operation time; while the Mann-Whitney $U$ test was used for rescue fentanyl dose and PCA connection time at the PACU, the NRS score at rest and during cough at $6,12,24,36,48$ hours after surgery, and the cumulative PCA consumption. 
Ordinal parameters, including the VPS and sedation score at the PACU and patient's overall satisfaction score, were compared using the Mann-Whitney U test, while categorical variables, including the American Society of Anesthesiologists (ASA) classification and the incidence of adverse events, were compared by a chi-squared test or Fisher's exact test. The changes over time in the VPS and sedation score at the PACU, the NRS score for pain, and cumulative PCA consumption in the ward were compared using repeated-measures analysis of variance.

Data are expressed as the mean $\pm \mathrm{SD}$ or number of patients (\%). $P$ values were two-tailed, and a $P$ value of less than 0.05 was considered to be statistically significant.

\section{Results}

A total of 103 patients were assessed for eligibility, and 33 patients were excluded for noncompliance with the study protocol; thus, 70 patients (35 for each group) were randomized. Among these, four operations were converted to open hysterectomy and two patients discontinued IV-PCA due to adverse effect (severe nausea). Finally, 31 patients in the fentanyl group and 33 in the sufentanil group were analyzed (Figure 1). There was no significant intergroup difference in baseline patient characteristics and operation and anesthesia times (Table 1).

At the PACU, the fentanyl group showed significantly higher VPS $(P=0.001)$ (Figure 2$)$ and higher rescue fentanyl administration $(22.1 \pm 26.1 \mathrm{vs}$. $8.3 \pm 17.3 ; P=0.005)$ than the sufentanil group, while the sedation score and adverse effects showed no intergroup differences (Table 2).

No significant differences were observed in the NRS scores for pain at rest and during cough in the ward during the 48-hour postoperative period (Figure 3 ), but the cumulative consumption of PCA during this period in the ward was significantly higher in the fentanyl group than in the sufentanil group (47.4 \pm 9.9 $\mathrm{ml}$ vs. $36.2 \pm 14.6 \mathrm{ml}, P=0.01$ ) (Figure 4 ).

Table 1. Demographic and clinical data

\begin{tabular}{llll}
\hline & Fentanyl $(\mathrm{n}=31)$ & Sufentanil $(\mathrm{n}=33)$ & $P$-value \\
\hline Age (year) & $49.9 \pm 8.0$ & $49.6 \pm 7.3$ & 0.819 \\
ASA (I/II) & $11 / 20$ & $13 / 20$ & 0.749 \\
Height $(\mathrm{m})$ & $1.56 \pm 0.05$ & $1.57 \pm 0.06$ & 0.280 \\
Weight $(\mathrm{kg})$ & $61.0 \pm 11.6$ & $61.5 \pm 8.1$ & 0.844 \\
Operation time & $74.4 \pm 32.8$ & $72.1 \pm 34.0$ & 0.790 \\
Anesthesia time & $115.2 \pm 32.7$ & $109.9 \pm 35.2$ & 0.509 \\
Values are mean \pm SD or number of patients. ASA: American Society of \\
Anesthesiologists physical status classification.
\end{tabular}

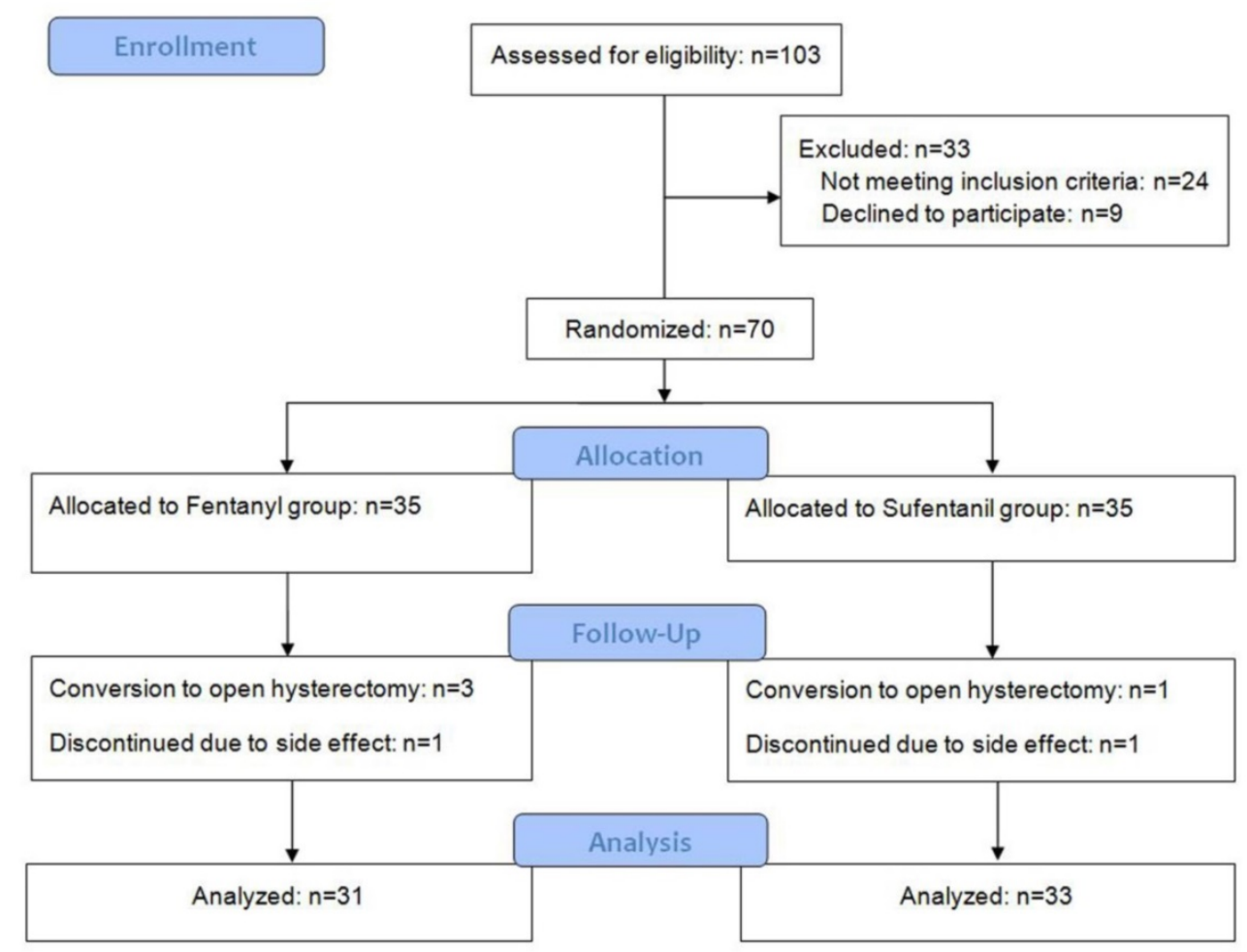

Figure 1. A flowchart describing patient recruitment, randomization, and withdrawal. 
(A)

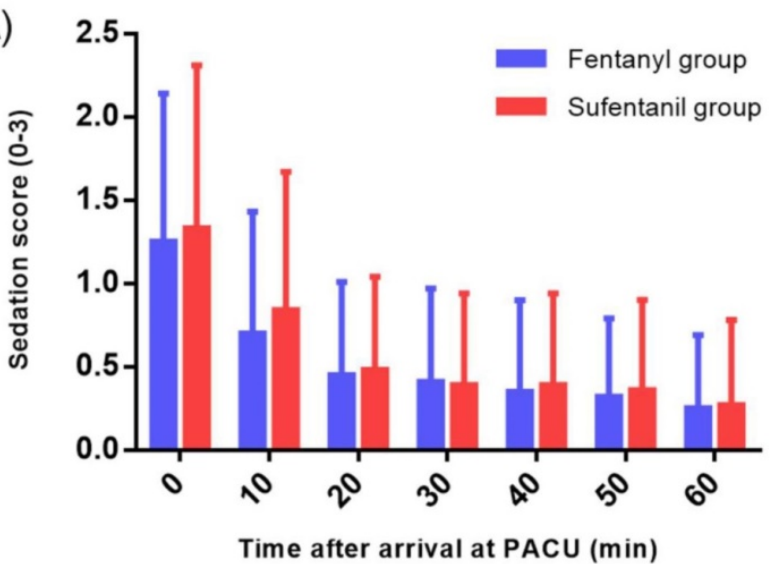

(B)

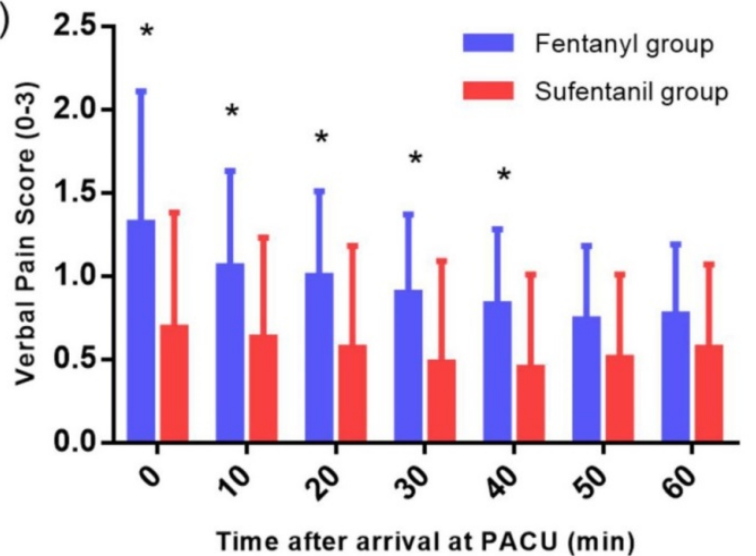

Figure 2. Sedation score (A) and verbal pain score (B) at the PACU. PACU: post-anesthesia care unit. Sedation score $(0=$ clearly conscious; $1=$ temporarily drowsy; 2 = drowsy but responsive to verbal communication; and 3 = drowsy without response to verbal communication $)$. Verbal pain score $(0=$ no pain, $1=$ mild pain, $2=$ moderate pain, and $3=$ intense pain). ${ }^{*} P<0.05$.

Table 2. Postoperative outcomes

\begin{tabular}{|c|c|c|c|}
\hline & $\begin{array}{l}\text { Fentanyl } \\
(\mathrm{n}=31)\end{array}$ & $\begin{array}{l}\text { Sufentanil } \\
(\mathrm{n}=33)\end{array}$ & $P$-value \\
\hline \multicolumn{4}{|l|}{ PACU outcomes } \\
\hline Rescue Fentanyl (mg) & $22.1 \pm 26.1$ & $8.3 \pm 17.3$ & 0.005 \\
\hline PCA connection time (min) & $11.6 \pm 9.6$ & $8.1 \pm 10.1$ & 0.094 \\
\hline Nausea & $5(16.1)$ & $6(18.2)$ & 1.000 \\
\hline Vomit & $1(3.2)$ & $1(3.0)$ & 1.000 \\
\hline \multicolumn{4}{|l|}{ Adverse effects at ward } \\
\hline $\begin{array}{l}\text { Nausea } \\
\text { (severe/moderate/mild/none) }\end{array}$ & $3 / 4 / 4 / 20$ & $7 / 6 / 6 / 14$ & 0.334 \\
\hline Vomiting & $2(6.5)$ & $1(3.0)$ & 0.607 \\
\hline Dry mouth & $15(48.4)$ & $6(18.2)$ & 0.016 \\
\hline Dizziness & $6(19.4)$ & $12(36.4)$ & 0.169 \\
\hline Urinary retention & $7(22.6)$ & $4(36.4)$ & 0.331 \\
\hline Headache & $7(22.6)$ & $13(39.4)$ & 0.183 \\
\hline Itchiness & $0(0)$ & $2(6.1)$ & 0.493 \\
\hline Shivering & $5(16.1)$ & $1(3.0)$ & 0.099 \\
\hline Respiratory depression & $0(0)$ & $0(0)$ & \\
\hline Satisfaction score $(0 / 1 / 2 / 3)$ & $1 / 0 / 10 / 20$ & $4 / 0 / 13 / 16$ & 0.276 \\
\hline
\end{tabular}

Values are mean \pm SD or number of incidence (\%). PACU: post-anesthesia care unit. Satisfaction score $(0=$ un-satisfied, $1=$ partial-satisfied, $2=$ satisfied, $3=$ fullsatisfied)
(A)

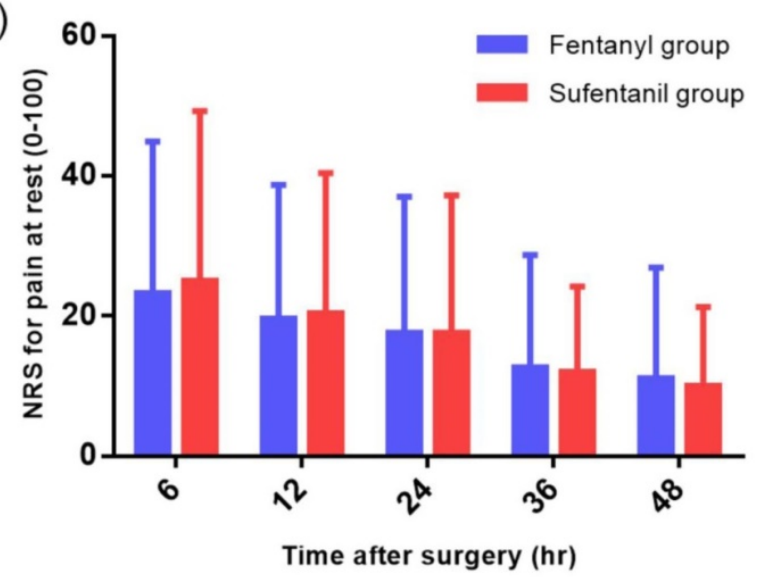

(B)

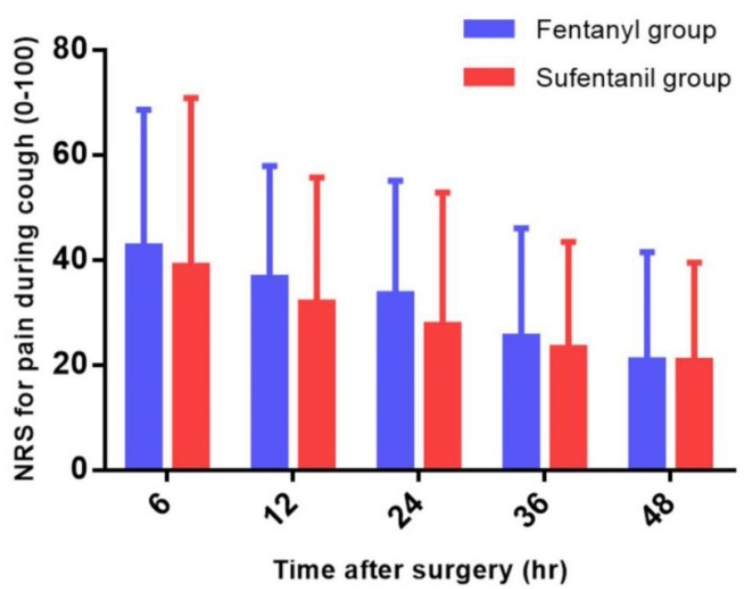

Figure 3. Numerical rating scale (NRS) for pain at rest $(A)$ and during cough $(B)$ in the ward.

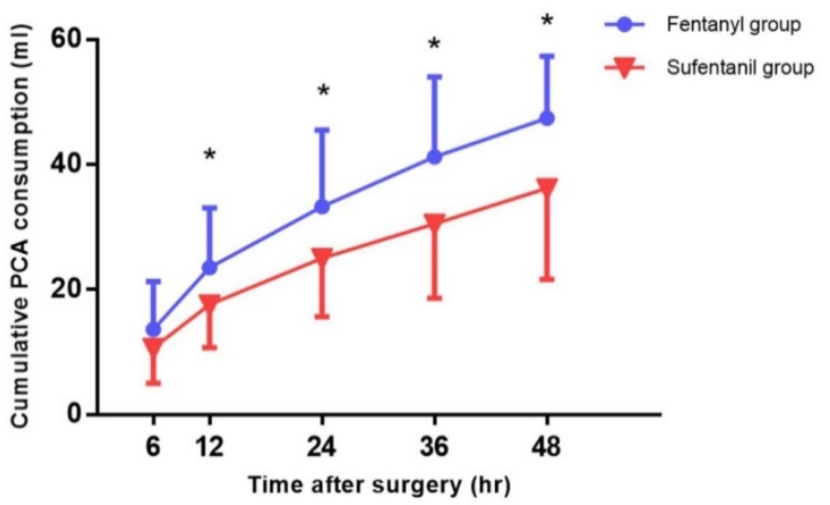

Figure 4. Cumulative patient-controlled analgesia (PCA) consumption in the ward. $* P<0.05$.

\section{Discussion}

In the present study, both fentanyl and sufentanil IV-PCA provided satisfactory postoperative pain control. Immediately after surgery, at the PACU, patients who received sufentanil 
showed lower pain scores and rescue analgesic requirement while the sedation score and incidence of adverse effects were not different between the two groups. In addition, over 48 hours after surgery, patients who received sufentanil IV-PCA showed less cumulative consumption compared to those who received fentanyl IV-PCA, with comparable analgesic efficacy and adverse effects (except the lower incidence of dry mouth in the sufentanil group).

Opioids are useful and potent analgesics for relieving moderate-to-severe postoperative pain. Morphine, fentanyl, and sufentanil are some of the commonly used opioids for IV-PCA [2, 13, 16, 17]. Morphine has been regarded as the first choice for IV-PCA and is the most commonly used and the most studied drug for IV-PCA [13]. However, the usefulness of morphine is sometimes compromised by its active metabolite-morphine-6-glucuronide-that also produces respiratory depression, especially in patients with renal insufficiency because the metabolite is mainly excreted by the kidney [18]. Fentanyl can be a good alternative for morphine-intolerant patients or those with altered renal function because it has no active metabolites and does not rely on renal excretion for elimination. Moreover, because of its lipophilicity, fentanyl has a quicker onset than morphine, possibly making it better suited for IV-PCA [13]. Therefore, fentanyl has been successfully used and is one of the most frequently used opioids for IV-PCA, especially in Korea [2].

A fentanyl progenitor, sufentanil, shows some advantages over other opioids. Sufentanil, like fentanyl, has no active metabolites. It is $5-10$ times more potent than its parent drug fentanyl $[5,19]$. The therapeutic index of sufentanil was markedly higher (26716) than those of morphine (71) and fentanyl (277) in preclinical models; this factor has clinical significance due to the lower incidence of respiratory depression with sufentanil than that with the other opioids [4, 16]. Sufentanil has a relatively rapid equilibration half-life ( $\mathrm{t}^{1} / 2 \mathrm{ke} 0 ; 6.2$ minutes) between plasma and brain, compared to 2.8 hours for morphine [20,21], and a relatively shorter duration of action than morphine and fentanyl [22]. Based on these properties, sufentanil can be considered to be appropriate and suited for IV-PCA. It is the most commonly used opioid for IV-PCA in China [17, 23], but there is relatively scarce evidence for its use in IV-PCA.

In our study, the sufentanil group consumed significantly less cumulative IV-PCA to maintain a pain score comparable with that in the fentanyl group. Mean cumulative consumption of PCA at $48 \mathrm{~h}$ after the operation in the sufentanil group was $36.2 \mathrm{ml}$, while that in the fentanyl group was $47.4 \mathrm{ml}$. Considering the weight of the participants, the PCA regimen was composed of about $4 \mu \mathrm{g} / \mathrm{kg}$ of sufentanil and $20 \mu \mathrm{g} / \mathrm{kg}$ of fentanyl in the respective groups, and during the postoperative $48-\mathrm{h}$ period, $3.14 \mu \mathrm{g} / \mathrm{h}$ $(0.0514 \mu \mathrm{g} / \mathrm{kg} / \mathrm{h})$ of sufentanil and $20.57 \mu \mathrm{g} / \mathrm{h}(0.3344$ $\mu \mathrm{g} / \mathrm{kg} / \mathrm{h}$ ) of fentanyl were respectively consumed. Given the comparable efficacy and adverse effects, the potency ratio was calculated as approximately 1:6.5 from the consumed dose. Therefore, the preset potency ratio of 1:5 in our study seemed to be somewhat greater in sufentanil than in fentanyl. In a previous study that compared fentanyl and sufentanil in IV-PCA after lumbar fusion [5], the potency ratio was 1:6 $(4 \mu \mathrm{g} / \mathrm{kg}$ for sufentanil and $24 \mu \mathrm{g} / \mathrm{kg}$ for fentanyl), and sufentanil IV-PCA showed comparable analgesic efficacy and lower incidence of postoperative nausea and vomiting (PONV).

A basal infusion may be required in sufentanil IV-PCA because of the short half-life of clearance, otherwise patients will require frequent boluses. However, previous studies have cautioned against using basal infusions routinely in IV-PCA for opioid-naive patients [13, 24-26] because of the increased risk of respiratory depression associated with opioids. Nevertheless, as described above, sufentanil has the highest therapeutic index and a lower respiratory depressive property in comparison with other opioids; [4, 16, 26, 27] thus, the potential problems associated with the use of basal infusions can be minimized with sufentanil. The major safety issue related to the use of IV-PCA is respiratory depression, which can be potentially life-threatening although it is not common [13]. The incidence of respiratory depression with IV-PCA has been reported to range from $0.19 \%$ to $5.2 \%$ [28]. The variations in the incidence could be attributed to the different definitions of respiratory depression, which is usually defined as reduced respiratory rate under 8 or 10 breaths per minute, sometimes including its depth and rhythm, and/or with oxygen saturation under $85 \%-90 \%$ [28]. Our data showed no respiratory depression associated with the use of both sufentanil and fentanyl (considering the definition of respiratory rate $<10$ or oxygen saturation $<90 \%$ for $>1 \mathrm{~min}$ ) despite the basal infusion. This might be attributable to the relatively higher therapeutic index of fentanyl and sufentanil.

The commonly observed adverse effects of opioid-based PCA are nausea and vomiting, pruritis, urinary retention, sedation, and, less commonly, respiratory depression and confusion [13]. Among these, PONV is the most common and most bothersome adverse effect of opioid-based IV-PCA, and the risk factors for PONV include female sex, a 
history of motion sickness or PONV, nonsmoking status, and postoperative opioid use [29]. Our study population consisted of female patients who were receiving opioids postoperatively; therefore, for antiemetic prophylaxis, ondansetron $8 \mathrm{mg}$ was administered. In previous studies comparing sufentanil and fentanyl $[5,6]$, the incidence of PONV was significantly lower in patients receiving sufentanil than in those receiving fentanyl. In contrast, our results showed no intergroup difference in the incidence of PONV and a higher incidence of moderate-to-severe PONV (39\% in the ward) than in the previous two studies $(4.8 \%-10 \%)$ when sufentanil used. In other studies, the incidence of PONV in sufentanil only IV-PCA was $31 \%-35 \%$ [30, 31], which was not much lower than our results. The higher incidence of PONV might be related to non-patient factors, including the type of surgical procedure (laparoscopy) and drugs used during anesthesia (inhalational agent than propofol), since it was reported that the incidence of PONV increased with the number of risk factors [32,33].

Dry mouth (xerostomia) is an underestimated opioid-induced side effect. Normal salivation is very important for oral health because it contributes to oral defense mechanisms, and impaired saliva secretion may cause dental caries or mucosal deterioration [34]. Opioids are well-known causes of dry mouth [35, 36], although the mechanism underlying this effect is unclear. A sufentanil-based IV-PCA regimen can be chosen instead of a fentanyl-based regimen to attenuate the incidence of dry mouth, although more evidence is required to support this advantage of sufentanil.

This study has some limitations. First, the 1:5 potency ratio of sufentanil to fentanyl seemed to be slightly higher for sufentanil. This might have affected the superior results showing lower pain scores and rescue analgesic requirement at the PACU and less cumulative PCA consumption of sufentanil. However, considering the consumed dose for comparable efficacy, the ratio was estimated to 1:6.5, which can be considered as an equivalent dose ratio of fentanyl to sufentanil in IV-PCA. Second, the prophylaxis for PONV might have been insufficient. The risk factors for PONV in this study were female sex, postoperative opioid use, and laparoscopy; therefore, it would have been better to administer not only ondansetron (serotonin antagonist) but also other antiemetics (e.g., droperidol and dexamethasone) for combination therapy.

\section{Conclusions}

In comparison with fentanyl, sufentanil showed comparable analgesic efficacy and safety (except the lower incidence of dry mouth) with less analgesic consumption under a potency ratio of 1:5 in IV-PCA over the 48-h period after TLH. Therefore, we suggest that sufentanil can be a useful alternative to fentanyl for IV-PCA.

\section{Abbreviations}

ASA: American Society of Anesthesiologists; BIS: bispectral index; KFDA: Korea Food and Drug Administration; MFDS: Ministry of Food and Drug Safety; NRS: numeric rating scale; PACU: post-anesthesia care unit; PCA: patient-controlled analgesia; PONV: postoperative nausea and vomiting; TLH: total laparoscopic hysterectomy; VPS: verbal pain score.

\section{Acknowledgements}

The contributors, who do not meet the criteria for authorship following recommendations of International Committee of Medical Journal Editors, are; Hyun Suk Hong, participating nurse investigator and Seol Hee Jeon, clinical pharmacist.

This manuscript was presented in part at the Poster Presentations Session in the Korean Society of Anesthesiologists Annual Meeting (KSA 2018), which took place in Seoul, Republic of Korea, Nov 8-10, 2018.

\section{Authors' contributions}

Study design/planning: IOL, SKO, and BGL

Study conduct: SKO, HJ, YSK, SGJ, JSP

Patient recruitment: HJ, SGJ, JSP

Patient allocation: $\mathrm{SHJ}$ (clinical pharmacist)

Data collection: SKO, BGL, and YSK

Data analysis: SKO, BGL, and YSK

Writing the draft paper: SKO, BGL, and IOL

Confirming the final paper: all authors

\section{Funding}

This work was supported in part by a research grant from the BC World Pharm. The opinions expressed in this paper are those of the authors and do not necessarily represent those of BC World Pharm.

\section{Competing Interests}

The authors have declared that no competing interest exists.

\section{References}

1. Macintyre PE. Safety and efficacy of patient-controlled analgesia. Br J Anaesth. 2001; 87: 36-46.

2. Kim K-M. Analysis of the current state of postoperative patient-controlled analgesia in Korea. Anesth Pain Med. 2016; 11: 28-35.

3. Stanley TH. The fentanyl story. J Pain. 2014; 15: 1215-26.

4. Bailey PL, Streisand JB, East KA, East TD, Isern S, Hansen TW, et al. Differences in magnitude and duration of opioid-induced respiratory 
depression and analgesia with fentanyl and sufentanil. Anesth Analg. 1990; 70: 8-15.

5. Kim DK, Yoon SH, Kim JY, Oh CH, Jung JK, Kim J. Comparison of the Effects of Sufentanil and Fentanyl Intravenous Patient Controlled Analgesia after Lumbar Fusion. J Korean Neurosurg Soc. 2017; 60: 54-9.

6. Lin CS, Lu G, Ruan LY, Gu MN. [Patient-controlled intravenous analgesia with sufentanil and fentanyl after thoracotomy: a comparative study]. Nan Fang Yi Ke Da Xue Xue Bao. 2006; 26: 240-1, 4.

7. Nieboer TE, Johnson N, Lethaby A, Tavender E, Curr E, Garry R, et al. Surgical approach to hysterectomy for benign gynaecological disease. Cochrane Database Syst Rev. 2009: Cd003677.

8. Gerbershagen HJ, Aduckathil S, van Wijck AJ, Peelen LM, Kalkman CJ, Meissner W. Pain intensity on the first day after surgery: a prospective cohort study comparing 179 surgical procedures. Anesthesiology. 2013; 118: 934-44.

9. Kehlet H, Jensen TS, Woolf CJ. Persistent postsurgical pain: risk factors and prevention. Lancet. 2006; 367: 1618-25.

10. Gan TJ. Poorly controlled postoperative pain: prevalence, consequences, and prevention. J Pain Res. 2017; 10: 2287-98.

11. Gupta A, Kaur K, Sharma S, Goyal S, Arora S, Murthy RS. Clinical aspects of acute post-operative pain management \& its assessment. J Adv Pharm Technol Res. 2010; 1: 97-108.

12. Shea RA, Brooks JA, Dayhoff NE, Keck J. Pain intensity and postoperative pulmonary complications among the elderly after abdominal surgery. Heart Lung. 2002; 31: 440-9.

13. Grass JA. Patient-controlled analgesia. Anesth Analg. 2005; 101: S44-61

14. Du Manoir B, Aubrun F, Langlois M, Le Guern ME, Alquier C, Chauvin M, et al. Randomized prospective study of the analgesic effect of nefopam after orthopaedic surgery. Br J Anaesth. 2003; 91: 836-41.

15. Tsui SL, Irwin MG, Wong CM, Fung SK, Hui TW, Ng KF, et al. An audit of the safety of an acute pain service. Anaesthesia. 1997; 52: 1042-7.

16. Palmer PP, Miller RD. Current and developing methods of patient-controlled analgesia. Anesthesiol Clin. 2010; 28: 587-99.

17. Zhang Y, Duan G, Guo S, Ying Y, Huang P, Zhang M, et al. To predict sufentanil requirement for postoperative pain control using a real-time method: A prospective observational cohort study. Medicine (Baltimore). 2016; 95: e3915.

18. Osborne RJ, Joel SP, Slevin ML. Morphine intoxication in renal failure: the role of morphine-6-glucuronide. Br Med J (Clin Res Ed). 1986; 292: 1548-9.

19. Maciejewski D. Sufentanil in anaesthesiology and intensive therapy. Anaesthesiol Intensive Ther. 2012; 44: 35-41.

20. Scott JC, Cooke JE, Stanski DR. Electroencephalographic quantitation of opioid effect: comparative pharmacodynamics of fentanyl and sufentanil. Anesthesiology. 1991; 74: 34-42.

21. Lötsch J, Skarke C, Schmidt H, Grosch S, Geisslinger G. The transfer half-life of morphine-6-glucuronide from plasma to effect site assessed by pupil size measurement in healthy volunteers. Anesthesiology. 2001; 95: 1329-38.

22. Hughes MA, Glass PS, Jacobs JR. Context-sensitive half-time in multicompartment pharmacokinetic models for intravenous anesthetic drugs. Anesthesiology. 1992; 76: 334-41.

23. Nie $Y$, Liu Y, Luo Q, Huang S. Effect of dexmedetomidine combined with sufentanil for post-caesarean section intravenous analgesia: a randomised, placebo-controlled study. Eur J Anaesthesiol. 2014; 31: 197-203.

24. Schug SA, Torrie JJ. Safety assessment of postoperative pain management by an acute pain service. Pain. 1993; 55: 387-91.

25. Sidebotham D, Dijkhuizen MR, Schug SA. The safety and utilization of patient-controlled analgesia. J Pain Symptom Manage. 1997; 14: 202-9.

26. Momeni M, Crucitti M, De Kock M. Patient-controlled analgesia in the management of postoperative pain. Drugs. 2006; 66: 2321-37.

27. Subrahmanyam M, Sreelakshmi B. Comparison of total intravenous anaesthesia using propofol with or without sufentanil in laparoscopic cholecystectomies. Indian J Anaesth. 2009; 53: 467-74.

28. Hagle ME, Lehr VT, Brubakken K, Shippee A. Respiratory depression in adult patients with intravenous patient-controlled analgesia. Orthop Nurs. 2004; 23 : 18-27; quiz 8-9.

29. Gan TJ, Meyer T, Apfel CC, Chung F, Davis PI, Eubanks S, et al. Consensus guidelines for managing postoperative nausea and vomiting. Anesth Analg. 2003; 97: 62-71, table of contents.

30. Dong CS, Zhang J, Lu Q, Sun P, Yu JM, Wu C, et al. Effect of Dexmedetomidine combined with sufentanil for post- thoracotomy intravenous analgesia:a randomized, controlled clinical study. BMC Anesthesiol. 2017; 17: 33.

31. Han L, Su Y, Xiong H, Niu X, Dang S, Du K, et al. Oxycodone versus sufentanil in adult patient-controlled intravenous analgesia after abdominal surgery: A prospective, randomized, double-blinded, multiple-center clinical trial. Medicine (Baltimore). 2018; 97: e11552.

32. Gan TJ. Postoperative nausea and vomiting--can it be eliminated? JAMA. 2002; 287: 1233-6.

33. Gan TJ, Diemunsch P, Habib AS, Kovac A, Kranke P, Meyer TA, et al. Consensus guidelines for the management of postoperative nausea and vomiting. Anesth Analg. 2014; 118: 85-113.

34. Mandel ID, Wotman S. The salivary secretions in health and disease. Oral Sci Rev. 1976: 25-47.

35. Götrick B, Åkerman S, Ericson D, Torstenson R, Tobin G. Oral pilocarpine for treatment of opioid-induced oral dryness in healthy adults. J Dent Res. 2004; 83: 393-7.
36. Bruera E, Belzile M, Neumann CM, Ford I, Harsanyi Z, Darke A. Twice-daily versus once-daily morphine sulphate controlled-release suppositories for the treatment of cancer pain. A randomized controlled trial. Support Care Cancer. 1999; 7: 280-3. 